Research Note

\title{
The Illusion of Progress in Students' Fluency - A Longitudinal Study of Students' Monologic Speech over an Academic Year
}

RoBert W. LONG III

Kyushu Institute of Technology

Kitakyushu, Japan

Corresponding author: long@dhs.kyutech.ac.jp

\section{About the author}

Robert Long has lived and worked in Japan for 24 years. He grew up in Florida and graduated from the University of Florida and Florida State University, with a Specialist Degree in Multilingual and Multicultural Education. He has traveled extensively and has worked at Kyushu Institute of Technology for the past 22 years, where he is a professor. His interests include jogging, gardening, art, yoga, and literature.

\section{Abstract}

This paper is about the issue of students' monologic speech, examining possible differences in fluency, production over levels of proficiency (as represented by TOEIC scores), and how this speech improves over an academic year. The data, which is based on the speech of 12 participants, was taken from the corpus Monologic and Dialogic Corpus 2019 (20,368 words and 42 subjects), and from the second corpus Monologic and Dialogic Corpus 2020 (16,997 words and 29 participants). Research questions focused on characterizing the speech in monologues of higher and lower proficiency Japanese EFL (English as a Foreign Language) learners in regards to the fluency variables of speaking time, articulation rate, mean length runs (MLRs), number of words, and percentage of silence. Furthermore, research aims focused on how acoustic, lexical and syntactical dysfluency might change over the year. Results showed that the average time of monologic speech was higher in the high-proficiency group than in the low-proficiency group in 2019 and 2020, but this difference was not statistically significant. In the high-proficiency group, there was a significant difference between 2019 and 2020 in meaningless syllables, whereas the other acoustic, lexical, and syntactical dysfluency variables showed no significant difference over the academic year 2019/2020. Further research will be conducted on how direct feedback might impact students' output.

Keywords: Fluency, Dysfluency, Monologic Speech, Acoustic, Syntactical Complexity 


\section{Introduction}

With more students entering higher education in every country, the need to sort and level students according to ability has become a necessity; thus, educators worldwide have been increasingly dependent on standardized tests. The main drawback of language-based exams is that they can only test passive skills and knowledge, such as reading, listening, and grammar, as the productive skills (writing and speaking) require too much time, money, and expertise to test properly. Without samples of student output, written or oral, educators have no other means of understanding students' progress except through test scores and the number of completed homework assignments, when, in fact, these are more of a gauge of students' persistence and diligence.

The issue of understanding and evaluating students' oral output brings enormous challenges. There are varied and complex variables to take into account of: accents, speaking rates, intonation, volume, along with acoustic, lexical, and syntactical dysfluency, which can greatly affect an evaluator's response. Indeed, coming to terms with fluency has been something that many researchers have debated, and proposals have been made on how it should be measured: (Foster, Tonkyn and Wigglesworth, 1996; Towell, Hawkins, and Bazergui, 1996; Yuan and Ellis, 2003; Ferreira and Bailey, 2004; Hirotani, Matsumoto and Fukada, 2012; Ginther, Dimova and Yang, 2010). Other researchers (Richards, Platt and Platt, 1992) took on the problem of dysfluency, particularly, the frequency of unfilled pauses as an indicator of non-fluency.

The lack of fluency and interactive competency has real meaning. By looking at how globalized our world has become, EFL students will often have to work and live in the U.S., U.K., Dubai, or someplace where English is imperative. While students may have passed some tests indicating their proficiency level, the real test is in their communicative competency, and much of that competency rests on fluency. No matter how intelligent and innovative they might be, their credibility will be adversely impacted if they cannot adequately transmit that knowledge and persuade others of their ideas. Thus, the focus of this paper is to describe fluency: how it differs over levels of proficiency and how it improves over an academic year - if at all, how significant are the differences in fluency variables with different scores? Finally, recommendations for improving students' monologic speech will be provided.

\section{Review of the Literature}

\section{Fluency}

As previously stated, fluency has been one of the most difficult concepts to define and understand, much less to be taught. There are many components to take into consideration, such as the use of formulaic language, rhythm, speaking rate, pausing, the number of errors, intonation, as several researchers note, (Bøhn, 2015; Housen \& Kuiken, 2009; Riggenbach, 1991). Fillmore (1979) has distinguished four kinds of native-speaker fluency: (a) "the ability to fill time with talk," which is commonly known as "disc-jockey fluency"; (b) "the ability to talk in coherent, reasoned and semantically dense sentences"; (c) "the ability to have appropriate 
things to say in a wide range of contexts" and (d) "the ability $\cdots$ to be creative and imaginative in language use" (p. 93). Many researchers have pointed out that fluency should be more widely defined (Brand and Götz, 2011; Crowther, Trofimovich, Isaacs and Saito, 2015) so as to emphasize the ability to produce speech that is rapid and comprehensible. Brumfit (1984) understood fluency as being "the maximally effective operation of the language system so far acquired by the students" (p. 57), in effect, stating that fluency refers more to natural language use instead of native-speaker production.

Common misconceptions still tend to prevail. One was that fluency develops with more proficiency, linearly, but Ellis (2009) suggested that this is not the case as there are trade-offs among fluency, accuracy, and complexity. For example, in regards to content, more complex issues, and a higher level of academic vocabulary would naturally impact the individual's speaking rate and pausing. This was also confirmed with Hirotani et al. (2012), who examined the fluency of novice-level students studying Japanese. They found a generally declining trend in fluency development in their longitudinal study. From their mixed model analysis, they identified such complexity factors as new vocabulary did impact the development of fluency.

As Lennon (1990) observed that fluency is, in fact, a performance phenomenon taking into account elements of the speakers' lexical range, syntactic complexity, idiomatic expression, appropriateness, and grammar. First, unnatural pauses are those that could indicate lexical or morphological uncertainty at other places. However, these pauses did function as a means to give the speaker time to consider how to proceed when they are related to ungrammatical English. In short, pausing was a way of relieving stress. Lewin et. al (1996) took this research issue a step further and focused on speaking anxiety, examining pauses, and verbal dysfluencies. The authors investigated whether speech disruptions, periods of silence, and a slower rate of speech were more prevalent in high-speech subjects than in their low-anxiety counterparts. They concluded that dysfluencies or pauses did not correlate with various measures of anxiety before or during the speech task. However, what remains to be better understood is that the type of speaking, monologues, or dialogues produce more anxiety or dysfluencies. Van Donzel and Koopsman-Van Beinum (1996) highlighted the importance of pausing strategies to structure the discourse.

\section{Techniques for Improving Fluency}

Furthermore, does fluency training positively impact fluency? Several techniques have been recommended by the Center for Teaching and Learning, University of Washington (Appendix 1). They include (a) echoing or shadowing in which the student repeats or echoes it as much as possible; (b) varying the focus on one's practice, thinking about pronunciation, rhythm, intonation; (c) reading a paragraph several times; (d) marking out the groups of thoughts in a paragraph; (e) marking linked points (where words are linked so as to practice these while recording); (f) reading and summarizing; (g) outlining a process; (h) recording yourself giving a short talk, and (i) practicing to complete grammar exercises orally. However, it should be noted that results about these techniques tend to be mixed up, particularly when factoring in motivation, age, an EFL or ESL context, and origin of the language learner. While fluency might be improved with the particular language forms or speech acts that were practiced, little is known about real-life encounters with varying kinds of pragmatic factors, and stress conditions can impact these gains.

Journal of Management and Training for Industries, Vol.8, No.2, 2021 
The issue here is that many studies have not taken accuracy into consideration when measuring fluency. One such study that examined how varying tasks can impact speech comprehensibility (Crowther et al., 2015, p. 80) discusses solely "segmental, word stress, rhythm, and speech rate" as examples of fluency categories. Similarly, Brand and Götz (2011), who focused on the correlation between speaking fluency and accuracy, used only temporal variables as speaking rate, length of speech runs or the number and the length of filled and unfilled pauses. Albino (2017) used a task-based approach in her teaching of ninth-grade learners and focused on a case study of picture-description tasks through the learner's speech recorded after the teaching. She found improvement in terms of speaking fluency by maximizing the learners' speed of speech production, increasing grammatical accuracy, elaborating on their utterances, and developing interactional language.

A second approach to improving fluency has been the use of adopting various strategies. Nakatani (2010) examined the impact of specific strategies on the oral abilities of 62 university students. He found from a 12-week experiment that little progress was observed in actual language gains regarding oral communicative strategies such as "paraphrasing, using gestures, and asking questions for clarification" (p. 117). Likewise, Rohani (2011) focused on the issue of whether the coping strategies would improve the production of $23 \mathrm{EFL}$ learners in regards to oral communication. He used a pre- and post-instruction questionnaire, in addition to interviews with the learners, and found that learners made more positive changes in their strategies for coping with speaking difficulties. Rohani also learned that there were gains in the learner's vocabulary and a reduction in the use of verbal communication; therefore, stress was decreased. However, what has not been fully understood and described is how fluency differs between lower-proficiency students and higher proficiency ones, and what some of the innovative techniques are to impact fluency.

\section{Rationale for the study}

Reinbold and Harris (2018) noted that the Japanese government's influence on English education has been profound. In 2006, in preparation for the new ten-year English program curriculum that would go into effect in 2007, courses for the university were to have multi-level skill objectives with a focus on reading, writing, listening, and speaking. Furthermore, for the planned three-level reading curriculum, each level has a 15-week course meeting with 90 minutes a week. Vocabulary building and intensive and extensive reading were included. The curriculum calls for targeted and assessed textbook-centered activities to improve comprehension, critical thinking, and summarizing skills as well as fluency-building work. Tahira (2012) criticizes MEXT (Ministry of Education, Culture, Sports, Science and Technology, Japan) expectations as obscure. Hagerman (2009) deems its guidelines ineffective while Okuno (2007) sees its English-education plans as improper and defective.

As for the curriculum at Kyushu Institute of Technology (KIT), a national university of engineering and science, the focus on the four skills in English teaching has reduced the skill of oral conversation to a minimum, except for two courses that have formal academic presentations as part of the skill base, though MEXT has emphasized comprehensive courses that include the four skills of listening, reading, speaking, and writing in a well-balanced manner. Thus, aside from the two courses, the other courses pay little attention 
to speaking, and students will have fewer opportunities to practice and develop this skill and improve their fluency.

\section{Research questions}

The results from this study indicate that one academic year of language education does not significantly affect fluency in spoken, spontaneous speech; however, it is crucial to collect more data to see if it either confirms or negates these findings. Thus, the research questions are as follows:

1. How can the speech (monologues) of Japanese L2 learners be described at upper and lower levels of proficiency? Are there significant differences between the two proficiency levels in regards to the fluency variables of speaking time, articulation rate, mean length runs (MLRs), number of words and percentage of silence?

2. How do acoustic, lexical, and syntactical dysfluency change over the year? Is there a significant difference?

\section{Corpora}

The interactions were interviewed and transcribed in 2018 and 2019. The first corpus (Monologic and Dialogic Corpus 2019, MDC 2019) has 20,368 words (42 participants) and was videotaped and transcribed from April to May 2019, whereas the second corpus (Monologic and Dialogic Corpus 2020, MDC 2020) has 16,997 words (29 participants) was videotaped in January and February 2020. These corpora and others can be found at $<$ genderfluency.com $>$, allowing educators to see the problems concerning balance, meaning, initiative, dysfluency (acoustic, syntactical and lexical), and the importance of developing strategic competency along with fluency. Students gave written permission for the videotapes to be used for research purposes and to be shown at conferences. Students were not paid for their interviews; the coding of the transcripts reflects the Conversational Analysis Convention.

\section{Participants}

42 students were interviewed for the first corpus (MDC2019), and 30 for the second, MDC2020. For this study, 12 students were selected, six from the lower to intermediate proficiency range (210-450) and six from a higher TOEIC range (645-920). All of the participants were Japanese, aged 18 to 19, except for two Korean students. It should also be noted that one of the Japanese students with the highest TOEIC score of 985 had lived in New Zealand for several years. University procedures and approval for the study were requested, granted, and followed, and all of the students agreed to be interviewed and have their conversations transcribed and studied. Student consent was obtained with the aim that the study would be reviewed by a university committee beforehand. These participants were all engineering majors. The sample size of the study is 12 students divided into two groups: a high-proficiency group and a low-proficiency group. Each group contained six students.

Journal of Management and Training for Industries, Vol.8, No.2, 2021 


\section{Interview}

Students were called in one by one for their interviews, and they were given the background of the research study and permission forms in both Japanese and English. Students were made aware that their monologues and dialogues were to be videotaped, transcribed, and used for research purposes. Participants knew they had the right to withdraw from the research once it started and that the focus was to acquire information about their fluency and grammatical accuracy. Their names of the students were abbreviated in the final corpora that were uploaded to the research website. Students were able to read the interview script out beforehand to avoid any lapses in comprehension that might impact the fluency data. The interview process began with a self-introduction monologue, which was then followed by a three-question dialogue about their friends, family, and classes.

\section{Preliminary Research}

Preliminary data were collected on two corpora regarding how fluency differs with varying levels of proficiency. The proficiency groups were divided into two groups with rather mixed results (Table 1). For monologic speech, some significance is seen, but this is rather negated when taking into consideration of dialogic speech. Articulation rates and speaking rates did show some significant increases as MLRs, and the number of words learners produce, but are these findings consistent with other corpora data?

In regard to improvement over an academic year, Long and Watanabe (2019) found that no significance

Table 1 Descriptive Statistics of Two Groups for 2018 Data and 2019 Data

\begin{tabular}{ccccc}
\hline & \multicolumn{2}{c}{2018 Data } & \multicolumn{2}{c}{2019 Data } \\
\cline { 2 - 5 } & Group 1 & Group 2 & Group 1 & Group 2 \\
\cline { 2 - 5 } & $(155-375)$ & $(470-770)$ & $(205-305)$ & $(560-985)$ \\
\hline Speaking time monologues & 110.2 & 163.4 & 163 & 216.5 \\
Speaking time dialogues & 174.6 & 189.7 & 258.1 & 250.3 \\
Speaking time total & 284.7 & 353.2 & 424.2 & 467.9 \\
Articulation rate & 0.69 & 1 & 0.89 & 1.67 \\
Speaking Rate A & 46.1 & 68 & 54.4 & 101.3 \\
Speaking Rate B & 41.2 & 62.7 & 50.7 & 98.3 \\
Fluency Differential (A-B) & 4.8 & 4.5 & 3.68 & 3.05 \\
Average Mean Length Runs & 11.2 & 27.2 & 10.5 & 84 \\
Number of Words & 162.6 & 312.3 & 321.5 & 664.6 \\
Percentage of Silence & 38.1 & 25.9 & 38.3 & 17.3 \\
\hline
\end{tabular}

Note: TOEIC scores are located under groups. 
Table 2 Descriptive Analysis of Fluency Variables

\begin{tabular}{llll}
\hline Variables & Pre-2018 & Post-2019 & Difference \\
\hline Articulation rate & 0.88 & 0.857 & -0.023 \\
Monologue speaking time & 155.413 & 169.756 & 14.343 \\
Speaking rate A & 58.32 & 53.38 & -4.94 \\
Speaking rate B & 52.973 & 49.113 & -3.86 \\
Fluency differential & 4.713 & 4.267 & -0.447 \\
Total speaking time & 328.467 & 387.807 & 59.34 \\
\hline
\end{tabular}

Note: This data is from (Long and Watanabe, 2019)

for the number of words spoken $\mathrm{t}(14)=-0.410, \mathrm{p}<0.687$; speaking rate A $\mathrm{t}(14)=-1.295, \mathrm{p}<0.216$; speaking rate $\mathrm{B} t(14)=0.930, \mathrm{p}<0.367$; articulation rate $\mathrm{t}(14)=0.280, \mathrm{p}<0.783$; or for the fluency differential between the two speaking rates, $\mathrm{t}(14)=0.5270, \mathrm{p}<0.605$ (Table 2).

\section{Statistical analysis}

For normally distributed independent variables, an independent T-test was used for estimating the mean difference between the two groups of students in 2019 and 2020. A Mann-Whitney test was used for nonnormally distributed independent variables. A paired T-test was used for estimating the mean difference between the two groups of students over the academic year 2019/2020 for normally distributed variables, whereas a Wilcoxon Signed-rank test was used for non-normally distributed variables. The continuous variables in this study were checked for normality using Shapiro-Wilk test. All statistical analyses were performed in SPSS (version 25).

\section{Results}

The mean time of monologue speech was higher in the high-proficiency group than in the low proficiency group in 2019 and 2020. However, this difference was not statistically significant ( $p=0.6, p=0.8$, respectively). There was a significant difference between the two groups in their articulation rate in both 2019 and $2020(p$ $<0.01)$. In addition, there was a significant difference between the two groups in MLR total syllables, MLR average, and percentage of silence in 2020 only ( $p<0.04, p<0.01, p<0.02$, respectively). On the other hand, there was no significant difference between the two groups in monologue speaking time, total speaking time, and the number of words in 2019 and 2020, and MLR total syllables, MLR average, and percentage of silence in 2019 only (see Table 3). In the low-proficiency group, there was a significant difference in monologue silence between 2019 and 2020 ( $p<0.02$ ), whereas all the other acoustic, lexical, and syntactical dysfluency variables showed no significant difference over the academic year 2019/2020 (Table 4). In the high-proficiency group, there was a significant difference between 2019 and 2020 in meaningless syllables $(p$ $<0.02)$. All the other acoustic, lexical, and syntactical dysfluency variables, however, showed no significant difference over the academic year 2019/2020 (Table 5). 
Table 3 Mean Difference in Fluency Variables between Two Groups

\begin{tabular}{|c|c|c|c|c|c|}
\hline Variable & Year & Group & Mean & Mean difference & $P$ value \\
\hline \multirow{4}{*}{ Monologue Speaking Time } & \multirow{2}{*}{2019} & Lower & 175.1 & \multirow{2}{*}{-31.3} & \multirow{2}{*}{0.642} \\
\hline & & Higher & 206.4 & & \\
\hline & \multirow{2}{*}{2020} & Lower & 229.9 & \multirow{2}{*}{-17.9} & \multirow{2}{*}{0.806} \\
\hline & & Higher & 247.7 & & \\
\hline \multirow{4}{*}{ Total Speaking Time } & \multirow{2}{*}{2019} & Lower & 437.1 & \multirow{2}{*}{-80.3} & \multirow{2}{*}{0.9} \\
\hline & & Higher & 517.4 & & \\
\hline & \multirow{2}{*}{2020} & Lower & 623.0 & \multirow{2}{*}{-174.6} & \multirow{2}{*}{0.589} \\
\hline & & Higher & 797.6 & & \\
\hline \multirow{4}{*}{ Articulation Rate } & \multirow{2}{*}{2019} & Lower & .8 & \multirow{2}{*}{-1.0} & \multirow{2}{*}{0.009} \\
\hline & & Higher & 1.8 & & \\
\hline & \multirow{2}{*}{2020} & Lower & .7 & \multirow{2}{*}{-1.1} & \multirow{2}{*}{0.000} \\
\hline & & Higher & 1.8 & & \\
\hline \multirow{4}{*}{ MLR Total Syllables } & \multirow{2}{*}{2019} & Lower & 364.5 & \multirow{2}{*}{-736.2} & \multirow{2}{*}{0.310} \\
\hline & & Higher & 1100.7 & & \\
\hline & \multirow{2}{*}{2020} & Lower & 498.2 & \multirow{2}{*}{-1143.2} & \multirow{2}{*}{0.041} \\
\hline & & Higher & 1641.3 & & \\
\hline \multirow{4}{*}{ MLR Average } & \multirow{2}{*}{2019} & Lower & 11.0 & \multirow{2}{*}{-170.7} & \multirow{2}{*}{0.132} \\
\hline & & Higher & 181.7 & & \\
\hline & ה חקטר & Lower & 9.6 & -374 & 2002 \\
\hline & 2020 & Higher & 47.0 & -51.4 & 0.002 \\
\hline & 2010 & Lower & 290.0 & -5877 & 0310 \\
\hline Number of Words & & Higher & 877.7 & & \\
\hline & חרח2 & Lower & 405.3 & -8553 & 0132 \\
\hline & $20 \angle 0$ & Higher & 1260.7 & -0.0 .0 & 0.102 \\
\hline & 2019 & Lower & 33.3 & 141 & 0201 \\
\hline Percentaoe of Silence & & Higher & 19.1 & 14.1 & \\
\hline & 2020 & Lower & 37.5 & 253 & 0021 \\
\hline & 2020 & Higher & 12.2 & 20.5 & 0.021 \\
\hline
\end{tabular}




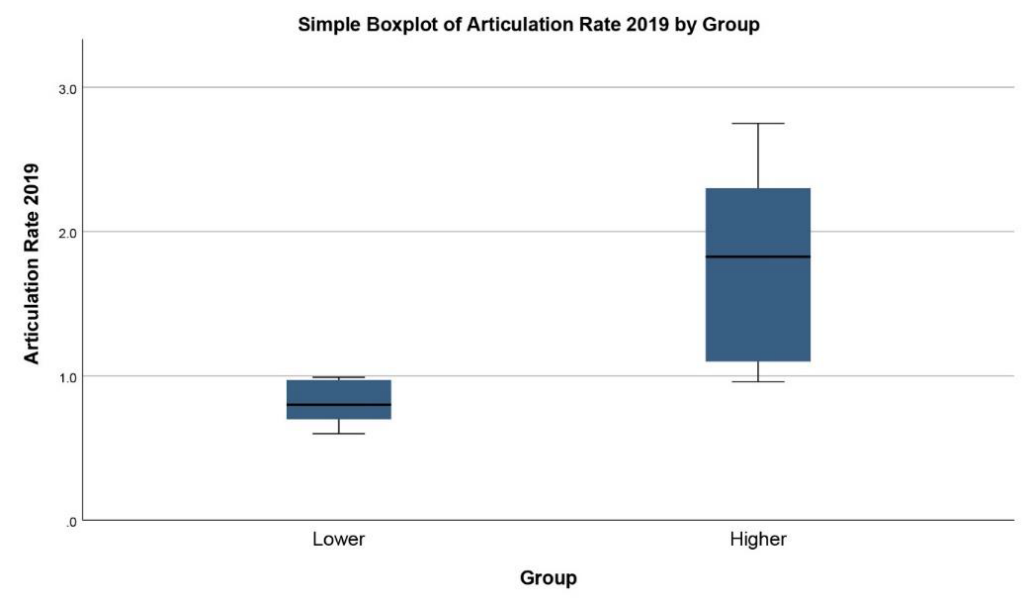

Fig. 1 Simple Boxplot of Articulation Rate 2019 by Group

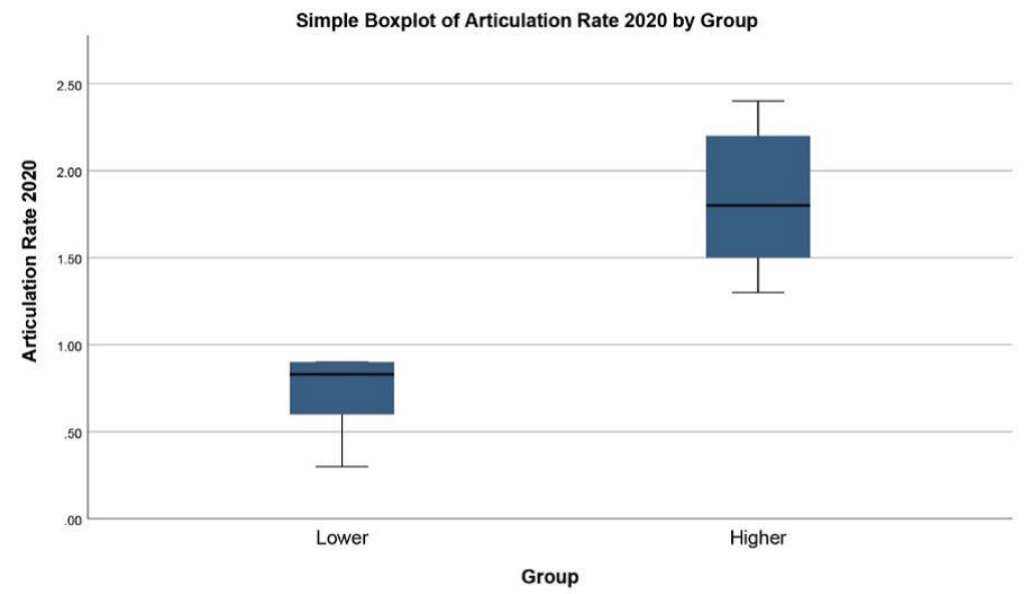

Fig. 2 Simple Boxplot of Articulation Rate 2020 by Group

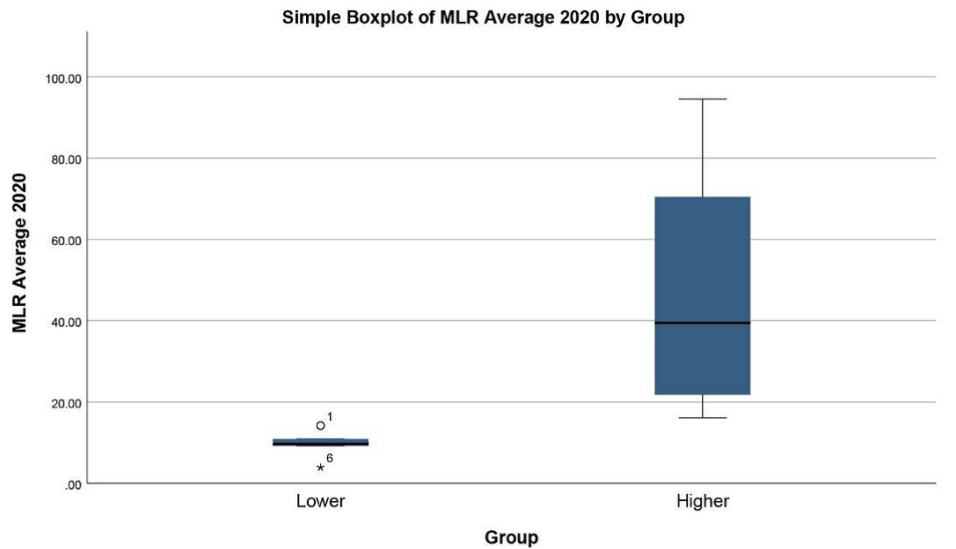

Fig. 3 Simple Boxplot of MLR Average 2020 by Group 
Table 4 Mean Difference in Acoustic, Lexical and Syntactical Dysfluency Variables over the Academic Year 2019/2020 in the Low-proficiency Group.

\begin{tabular}{|c|c|c|c|c|}
\hline Variable & Over the Year & Mean & Mean Difference & $P$ value \\
\hline \multirow{2}{*}{ Micropauses } & 2019 & 7.7 & \multirow{2}{*}{-3.8} & \multirow{2}{*}{0.064} \\
\hline & 2020 & 11.5 & & \\
\hline \multirow{2}{*}{ Cross-talk pausing } & 2019 & 2 & \multirow{2}{*}{-9.9} & \multirow{2}{*}{0.102} \\
\hline & 2020 & 11.9 & & \\
\hline \multirow{2}{*}{ Total Amount of Silence } & 2019 & 164.1 & \multirow{2}{*}{-64.5} & \multirow{2}{*}{0.09} \\
\hline & 2020 & 228.6 & & \\
\hline \multirow{2}{*}{ Monologue Silence } & 2019 & 62.4 & \multirow{2}{*}{-31.8} & \multirow{2}{*}{0.018} \\
\hline & 2020 & 94.2 & & \\
\hline \multirow{2}{*}{ Percentage of Silence } & 2019 & 33.3 & \multirow{2}{*}{-4.3} & \multirow{2}{*}{0.657} \\
\hline & 2020 & 37.5 & & \\
\hline \multirow{2}{*}{ Length of Pauses } & 2019 & 5.8 & \multirow{2}{*}{-0.3} & \multirow{2}{*}{0.874} \\
\hline & 2020 & 6.1 & & \\
\hline \multirow{2}{*}{ Mispronounced Words } & 2019 & 1.8 & \multirow{2}{*}{-0.7} & \multirow{2}{*}{0.394} \\
\hline & 2020 & 2.5 & & \\
\hline \multirow{2}{*}{ Word Fragments } & 2019 & 1 & \multirow{2}{*}{-2} & \multirow{2}{*}{0.076} \\
\hline & 2020 & 3 & & \\
\hline \multirow{2}{*}{ Use of L1 } & 2019 & 4 & \multirow{2}{*}{-6.2} & \multirow{2}{*}{0.287} \\
\hline & 2020 & 10.2 & & \\
\hline \multirow{2}{*}{ Abandoned Sentences } & 2019 & 0.2 & \multirow{2}{*}{0.2} & \multirow{2}{*}{0.363} \\
\hline & 2020 & 0 & & \\
\hline Retracino & 2019 & 5.5 & -32 & 0273 \\
\hline & 2020 & 8.7 & & \\
\hline Renetition & 2019 & 16.8 & -19 & 0.189 \\
\hline 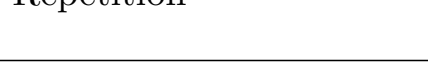 & 2020 & 35.8 & 10 & 0.108 \\
\hline MLR Total Syllables & 2019 & 364.5 & -1337 & 0.084 \\
\hline & 2020 & 498.2 & & \\
\hline MLR Averaoge & 2019 & 11 & 1.5 & 0.448 \\
\hline 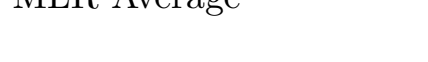 & 2020 & 9.6 & & \\
\hline Number of Words & 2019 & 290 & -115.3 & 0080 \\
\hline 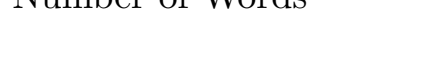 & 2020 & 405.3 & 110.0 & 0.000 \\
\hline Meaninoless Syllables & 2019 & 28 & -383 & 0063 \\
\hline & 2020 & 66.3 & & \\
\hline
\end{tabular}


Table 5 Mean Difference in Acoustic, Lexical and Syntactical Dysfluency Variables over the Academic Year 2019/2020 in the High-proficiency Group

\begin{tabular}{|c|c|c|c|c|}
\hline Variable & Over the Year & Mean & Mean Difference & $P$ value \\
\hline \multirow{2}{*}{ Micropauses } & 2019 & 5.7 & \multirow{2}{*}{-7.8} & \multirow{2}{*}{0.456} \\
\hline & 2020 & 13.5 & & \\
\hline \multirow{2}{*}{ Cross-talk pausing } & 2019 & 3.3 & \multirow{2}{*}{3.3} & \multirow{2}{*}{0.363} \\
\hline & 2020 & .0 & & \\
\hline \multirow{2}{*}{ Total Amount of Silence } & 2019 & 54.9 & \multirow{2}{*}{-34.7} & \multirow{2}{*}{0.349} \\
\hline & 2020 & 89.5 & & \\
\hline \multirow{2}{*}{ Monologue Silence } & 2019 & 21.3 & \multirow{2}{*}{-8.4} & \multirow{2}{*}{0.439} \\
\hline & 2020 & 29.7 & & \\
\hline \multirow{2}{*}{ Dialogue Silence } & 2019 & 33.6 & \multirow{2}{*}{-26.2} & \multirow{2}{*}{0.352} \\
\hline & 2020 & 59.8 & & \\
\hline \multirow{2}{*}{ Percentage of Silence } & 2019 & 19.1 & \multirow{2}{*}{6.9} & \multirow{2}{*}{0.229} \\
\hline & 2020 & 12.2 & & \\
\hline \multirow{2}{*}{ Length of Pauses } & 2019 & 2.9 & \multirow{2}{*}{.3} & \multirow{2}{*}{0.313} \\
\hline & 2020 & 2.7 & & \\
\hline \multirow{2}{*}{ Mispronounced Words } & 2019 & 2.5 & \multirow{2}{*}{1.2} & \multirow{2}{*}{0.523} \\
\hline & 2020 & 1.3 & & \\
\hline \multirow{2}{*}{ Word Fragments } & 2019 & 2.5 & \multirow{2}{*}{-2.0} & \multirow{2}{*}{0.314} \\
\hline & 2020 & 4.5 & & \\
\hline \multirow{2}{*}{ Use of L1 } & 2019 & .7 & \multirow{2}{*}{-5} & 0656 \\
\hline & 2020 & 1.2 & & \\
\hline A handoned Sontencos & 2019 & .7 & 7 & 0100 \\
\hline & 2020 & .0 & & \\
\hline Retracing & 2019 & 6.2 & 0 & 1000 \\
\hline & 2020 & 6.2 & & \\
\hline Ponotition & 2019 & 8.8 & 0.8 & 0145 \\
\hline & 2020 & 18.7 & & \\
\hline MI P Total Sullobloc & 2019 & 1100.7 & 5407 & 0246 \\
\hline MLL Total sy & 2020 & 1641.3 & -340.1 & 0.240 \\
\hline MI P A & 2019 & 181.7 & 1347 & 0268 \\
\hline & 2020 & 47.0 & & \\
\hline Number of Words & 2019 & 877.7 & 3820 & 0325 \\
\hline 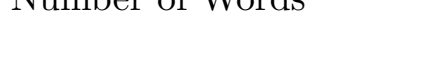 & 2020 & 1260.7 & -000.0 & 0.020 \\
\hline Meaningless Syllables & 2019 & 19.3 & 350 & 0018 \\
\hline & 2020 & 54.3 & & \\
\hline
\end{tabular}




\section{Conclusion}

In short, these mixed results show the complexity of the fluency and dysfluency of students' oral spontaneous speech. As there was no significant difference between the two groups in monologue speaking time, total speaking time, and the number of words in 2019 and 2020, it is possible to state that students are not aware of their output regarding fluency, production, and accuracy. Although results did show in the low-proficiency group, there was a significant difference in monologue silence between 2019 and 2020, which indicates that perhaps this group benefited the most from the instruction. In contrast, in the high-proficiency group, (while having a significant difference between 2019 and 2020 in meaningless syllables), all of the other acoustic, lexical, and syntactical dysfluency variables showed no significant difference over the academic year 2019/2020. The students' lack of progress in fluency shows that traditional teaching methods are flawed, particularly insofar as getting students to understand the nature and problems of their own output. However, these mixed results highlight the challenge of getting students to be more aware of their output and to self-reflect and actively improve their speaking.

This issue is problematic in that it requires that students should be conscious of videotaping, transcribing, or close listening in relation to speaking rate, vocabulary, repetition, retracing, sub-vocalizations, MLRs and other issues. Further, it requires that teachers have a means of coherent and consistent practice to address those issues as instructions. To most educators, unmotivated students are unlikely to take much time, energy, and analysis to improve. Furthermore, personality plays a significant part with shyer students having more problems in making progress, particularly in the number of words produced and MLRs.

Thus, the key question is how educators should stimulate unmotivated students and withdrawn students in their classes? For many teachers, various fluency tasks (such as shadowing, reading aloud protocols, question-answer roleplays) have been the key means, but these tasks may provide a false sense of fluency. Speaking involves a variety of social and pragmatic variables. Thus, it is recommended that more open-ended roleplays and conversational maps be offered to students that allow for choices, decisions, responses, and initiation so as to better simulate real-life interactions.

The results of this study indicate that progress in students' grammatical accuracy is slow over an academic year as there is little awareness about the fluency and dysfluency of their spontaneous speech. Any improvement in fluency might be noted more with the lower proficiency students than with a higher proficiency group because students with lower proficiency need to make more effort. More attention and individual feedback should be one solution to improving these two domains of oral speech.

\section{References}

Albino, G., 2017. "Improving Speaking Fluency in a Task-based Language Teaching Approach: The Case of EFL Learners at PUNIV-Cazeng", SAGE Open, April-June, pp. 1-11.

Bøhn, H., 2015. "Assessing EFL Spoken Language", SAGE Open, Vol. 5, No. 4, pp. 1-12. 
doi:10.1177/2158244015621956.

Brand, C. \& Götz, S., 2011. "Fluency versus Accuracy in Advanced Spoken Learner Language: A Multi-method Approach", International Journal of Corpus Linguistics, Vol. 16, pp. 255-275. doi:10.1075/ijcl.16.2.05bra.

Brumfit, C. J., 1984. Communicative Methodology in Language Teaching: The Roles of Fluency and Accuracy, Cambridge University Press: Cambridge.

Crowther, D., Trofimovich, P., Isaacs, T. \& Saito, K., 2015. "Does a Speaking Task Affect Second Language Comprehensibility?", Modern Language Journal, Vol. 99, pp. 80-95. doi:10.1111/modl.12185.

Ferreira, F. \& Bailey, K., 2004. "Disfluencies and Human Language Comprehension", TRENDS in Cognitive Science, Vol. 8, No. 5, pp. 231-237.

Fillmore, L. W., 1979. "Individual Differences in Second Language Acquisition", In Fillmore, C., Kempler, D. and Wang, W. Y. S. (eds), Individual Differences in Language Ability and Language Behavior, New York, USA: Academic Press.

Foster, P, Tonkyn, A. \& Wigglesworth, G., 2000. "Measuring Spoken Language: A Unit for All Reasons", Applied Linguistics, Vol. 21, No. 3, pp. 354-375.

Ginther, A., Dimova, S. \& Yang, R., 2010. "Conceptual and Empirical Relationships between Temporal Measures of Fluency and Oral English Proficiency with Implications for Automated Scoring", Language Testing, Vol. 27, No. 3, pp. 379-399.

Hagerman, C., 2009. "English language policy and practice in Japan", Osaka Joshigakuin Daigaku Kiyo, Vol. 6, pp. 1-18.

Hirotani, M., Matsumoto, K. \& Fukada, A., 2012. "Longitudinal Study on Fluency among Novice Learners of Japanese", In L. Bradley \& S. Thouësny (Eds.), CALL: Using, Learning, Knowing, EUROCALL Conference, Gothenburg, Sweden, Proceedings (pp. 129-133). Research-publishing.net Dublin 2012.

Housen, A. \& Kuiken, F., 2009. "Complexity, Accuracy, and Fluency in Second Language Acquisition", Applied Linguistics, Vol. 30, pp. 461-473. doi:10.1093/applin/amp048.

Lennon, P., 1990. Investigating Fluency in EFL: A Quantitative Approach. Language Learning, Vol. 40, No. 3, pp. 387-417. Retrieved from http://dx.doi.org/10.1111/j.1467-1770.1990.tb00669.x, Oct. 31, 2020 .

Lewin, C., Wolgers, G. \& Herlitz, A., 2001. "Sex Differences Favoring Women in Verbal but not in Visuospatial Episodic Memory", Neuropsychology, Vol. 15, pp. 165-173. doi:10.1037/0894-4105.15.2.165.

Long, R. \& Watanabe, H., 2019. "Gains and Losses in Fluency Over an Academic Year: A Longitudinal Study of Japanese Students' L2. Joint presentation", Paper Presented at the 21st ICTEL2019 International conference on Teaching, Education \& Learning, October 14-15, Prague, The Czech Republic.

Nakatani, Y., 2010. "Identifying Strategies That Facilitate EFL Learners'Oral Communication: A Classroom Study using Multiple Data Collection Procedures", The Modern Language Journal, Vol. 94, pp. 116-137.

Okuno, H., 2007. "A Critical Discussion on The Action Plan to Cultivate "Japanese with English Abilities"”, The Journal of Asia TEFL, Vol. 4, No. 4, pp. 133-158. 
Reinbold, L. \& Harris, Harry, 2018. "MEXT Guidelines and Revamping Our University EFL Reading Curriculum", Journal of Education Faculty of Hakuoh University, Vol. 11, No. 4, pp. 75 - 91.

Richards, J. C., Platt, J. \& Platt, H., 1992. Longman Dictionary of Language Teaching, Applied Linguistics, Longman, Harlow, Essex.

Riggenbach, H., 1991. "Towards an Understanding of Fluency: A Microanalysis of Nonnative Speaker Conversations", Discourse Analysis, Vol. 14, No. 4, pp. 423-443.

Rohani, S., 2011. "Impact of Task-based Learning on Indonesian Tertiary EFL Students' Employment of Oral Communication Strategies", The International Journal of Interdisciplinary Social Sciences, Vol. 5, No. 10, pp. 85-102.

Tahira, M., 2012. "Behind MEXT's New Course of Study Guidelines", The Language Teacher, Vol. 36, No. 3, pp. 3-8.

Towell, R., Hawkins, R. \& Bazergui, N., 1996. "The Development of Fluency in Advanced Learners of French", Applied Linguistics, Vol. 17, No. 1, pp. 84-115.

Van Donzel, M. E. \& Koopsman-Van Beinum, F. J., 1996. Pausing Strategies in Discourse in Dutch, Retrieved from http://www.asel.udel.edu/icslp/cdrom/vol2/505/a505.pdf, Oct. 31, 2020.

Yuan, F. \& Ellis, R., 2003. "The Effects of Pre-task Planning and On-line Planning on Fluency, Complexity, and Accuracy in L2 Monologic Oral Production", Applied Linguistics, Vol. 24, No. 1, pp. 1-27.

\section{Appendix}

1. University of Washington, Center for Teaching and Learning. Retrieved from: https://www. washington.edu/teaching/programs/international-teaching-assistant-program/resourcesfor-international-tas/communication-resources-for-international-tas/strategies-forenhancing-english-language-fluency-general-fluency/

2. The data for this paper was presented as a keynote presentation at the online ICSSH conference held on September 19-21, 2020. 